\title{
Advancing Measurement of Foreign Policy Similarity
}

\author{
Vito D'Orazio \\ University of Texas at Dallas \\ School of Economic, Political, and Policy Sciences \\ dorazio@utdallas.edu *
}

April 13, 2015

Extant theoretical literature in International Relations has suggested that the similarity of foreign policy preferences is a meaningful and important concept. The commonly used measures of this concept $-\tau_{b}$ and, more recently, the $S$-score - are problematic in two ways. First, as algorithms, neither operationalize the concept in a manner consistent with how students of IR theorize foreign policy similarity. Specifically, $\tau_{b}$ is not a measure of similarity; it is a measure of concordance or rank-order similarity. Although $S$ is a measure of similarity, it does not account for the degree of third-party relationships, only the symmetry of such relationships. A new algorithm, $D$, which incorporates the degree of mutual relationships into the measurement of foreign policy similarity, is introduced. The resulting $D$-score is standardized, as opposed to the $S$-score which has four commonly used versions in addition to several others that may be subjectively defined. Second, the input data for measures of foreign policy similarity are typically data on formal alliances. Generally speaking, alliances are a granular indicator of an underlying, military-strategic relationship between states, more generally referred to as military cooperation. As such, the policy portfolio used to calculate $D$ can include additional indicators of military cooperation. Alliances, joint military exercises (for which new data has been collected), arms transfers, and multinational combat and peacekeeping operations are combined using a graded response model to estimate military cooperation as a latent trait. The latent trait is used as input data to calculate the $D-$ score, which is directly compared with the $S$ - score and shown to be consistent with intuitive notions of policy similarity while the $S$-score is not. In a replication study, the new measure is shown to not be substitutable with the $S$-score.

* Thanks to David Carter, Andrew Enterline, Phil Schrodt, and James Honaker for comments on earlier drafts. 


\section{Introduction}

The United States and Argentina have shared a defensive alliance through the Organization of American States since 1947. The US has had a similar alliance with the United Kingdom through the North Atlantic Treaty Organization since 1949. When the UK went to war with Argentina over the disputed Falkland Islands in 1982, the world wanted to know with whom the US would side.

Answering these sorts of questions is the reason that measures of foreign policy similarity have been developed (Altfeld and Bueno de Mesquita, 1979; Signorino and Ritter, 1999, Hage, 2011). Extant quantitative literature in International Relations (IR) has also shown these measures to be useful in a variety of theory-testing applications (Morrow, Siverson and Tabares, 1998; Bapat, 2007; Leeds, 2003, Long and Leeds, 2006; Gartzke, 2007; Moore, 2010). Foreign policy similarity, however, can be interpreted in a variety of ways and there seems to be some confusion as to what concept the commonly used measures of policy similarity-current Signorino and Ritter's $S$ - score and previously Altfeld and Bueno de Mesquita's $\tau_{b}$-are operationalizing.

Bapat (2007) states that "Signorino and Ritter's weighted measure of $S$ captures the political affinity between target and host states" (p. 276). Morrow, Siverson and Tabares (1998) utilize $\tau_{b}$ to "operationalize common interests in a dyad of states" (p. 654). In its original formulation, the intent of $\tau_{b}$ is to measure the extent to which two state's foreign policy commitments, based on common revealed preferences, are similar Bueno de Mesquita, 1975; Altfeld and Bueno de Mesquita, 1979). While these specifications are similar, they are describing a concept represented by neither $S, \tau_{b}$, nor one of the more recent measures proposed by Hage (2011).

$\tau_{b}$ is a measure of concordance, or rank-order similarity, derived by calculating Kendall's $\tau_{b}$ statistic on a matrix containing data on the foreign policies of two states Bueno de Mesquita, 1975; Altfeld and Bueno de Mesquita, 1979). Despite its widespread use for nearly two decades, concordance is not the similarity of reveal preferences, as Signorino and Ritter (1999) point out. However, $\tau_{b}$ made two vital contributions to IR that are utilized by its successor measure, the $S-$ score. First, seeing as it is constructed from the relationships of actors with every other actor in the system, $\tau_{b}$ is a network measure. Second, $\tau_{b}$ reflects the intuition that observed foreign policies are revelations of underlying preferences. Each of these contributions is foundational for $S$.

The $S$ algorithm calculates a geometric distance, commonly the Euclidean distance, between 
two vectors where each vector corresponds to the foreign policies of two states ${ }^{1}$ As such, $S$ is identical to structural equivalence, a commonly used concept in social network analysis Lorraine and White, 1971; Wasserman and Faust, 1994). Structural equivalence reflects the symmetry of common relationships in a network and is used to identify actors that share a similar networkposition.

In terms of measuring foreign policy similarity, a similar network position does not imply the similarity of revealed preferences. For example, Mexico has a strong relationship with the United States and a relatively weak relationship with most other states in the international system. The same is true for Israel and the Philippines. Although each of these states share a similar network position, not much can be inferred about their political affinity based on this information.

The concern lies in the fact that $S$ fails to capture the degree to which foreign policy commitments are similar. According to the $S$ - score, two states with strong common relationships are equivalent to two states with weak or non-existent common relationships. The mutual lack of a relationship is especially troublesome, since two states that have no relationship with any other state have symmetrical foreign policies but are not likely to have any affinity for one another.

I propose a new algorithm, $D$, for calculating foreign policy similarity. $D$ builds upon previous measures by keeping the policy portfolio, network-based approach of $\tau_{b}$ and the symmetry-based scoring of $S$ but also incorporates the degree of third-party relationships. Using $D$, two states without a third-party relationship are not considered similar, despite the fact that they are symmetrical. Two states with strong third-party relationships upweight the similarity score more than those with weak third-party relationships.

Like the $S$-score, $D$ may be calculated with continuous data and a multidimensional foreign policy portfolio. Traditionally, the foreign policy portfolio has consisted for formal alliances, and students of IR have taken notice of the shortcomings of using a unidimensional portfolio consisting of formal alliances (Bennett and Rupert, 2003, Hage, 2011, Sweeney and Keshk, 2005, Li, 2005. Fearon, 1997; Morrow, 2000). Bueno de Mesquita (1981), Signorino and Ritter (1999), and Gartzke (2007) suggest other potential policies to incorporate, but none have succeeded in supplanting formal alliances.

The second contribution of this research is to present a new measure of military cooperation

\footnotetext{
${ }^{1} S$ also provides the flexibility to include weightings and transformations, both of which are discussed below.
} 
to use as input for computing foreign policy similarity. Specifically, military cooperation is conceptualized as a latent trait of a dyadic relationship that is revealed through different foreign policies including alliances, joint military exercises, arms transfers, and multinational combat and peacekeeping operations. These indicators are combined to estimate military cooperation using the graded response model (GRM) from item response theory (Samejima, 1997). The $D-$ score is calculated using this estimate of military cooperation as its input.

This article proceeds in three main sections. First, the algorithm used to construct $S$ is discussed in detail and the new algorithm, $D$, is introduced. Second, the primary concerns associated with relying on alliance data and a unidimensional policy portfolio are stated, and a new estimate of military cooperation using a GRM is introduced. Third, $D$ is calculated and compared with $S$ and Hage's measures using data from 1971-2000. Finally, two articles are replicated using the $D$-score to demonstrate these measures are not substitutable.

\section{Algorithms for Foreign Policy Similarity}

Foreign policy similarity is not a dyadic measure - it is a network measure whose value depends not only on the dyadic relationship but on each member of the dyad's third-party relationships with every other state in the system. The original motivation for measuring foreign policy similarity grew out of the early expected utility literature where researchers asked with whom a state would be more likely to side with in the event of war (Bueno de Mesquita, 1975, 1981). While similar foreign policy portfolios are meant to be indicative of a strong preference, dissimilar ones are indicative of a weak preference.

Currently, the predominant measure of foreign policy similarity is the $S$ - score (Signorino and Ritter, 1999). Similar to the previous measure of foreign policy similarity, $\tau_{b}$, the $S-$ score is calculated by performing some algorithm on the foreign policy portfolios of two states. The $S$ algorithm is a distance metric where symmetric portfolios equate to high similarity and asymmetric portfolios to low similarity.

Suppose we have a two sets of the same actors $i=1, \ldots, n$ and $k=1, \ldots, m$. The sociomatrix $\mathbf{P}$ is then an $n \times m$ matrix where each cell contains data about the relation among each pair of actors, $p_{i k} \forall i \neq k$. Each row, $p_{i}$, refers to the vector corresponding to State $i$ 's policy portfolio. Let 
$w$ equal a vector of weights where $w_{k}$ is a weight for each $k 2^{2}$ Finally, let $L$ be a vector of scoring rules which maps $p_{i}$ to some closed interval along the real number line $3^{3} \Delta^{\text {max }}$ equals the difference between the maximum and minimum possible values after the mapping.

As is the case in practice, we will look at the equation for calculating $S$ for a single policy dimension where the sum of the weighting vector equals 1 and we assume that no mapping for the scoring rules is necessary. The original series of equations (Signorino and Ritter 2010, 127) can then be written as:

$$
S\left(p_{i}, p_{j}, W, L\right)=1-2\left(\frac{1}{\Delta^{\max }}\right) \sum_{k=1}^{n}\left(w_{k, k}\left|p_{i k}-p_{j k}\right|\right)
$$

As a measure of the symmetry of two state's policy portfolios, $S$ is fundamentally a measure of the social network analysis concept known as structural equivalence, albeit a weighted and transformed version 4 Unfortunately, structural equivalence is not the concept we want when measuring foreign policy similarity because symmetry is not affinity. To demonstrate this point graphically, the $S$ algorithm is visualized in Figure 1 .

In Figure 1 we have a set of six states, $\{\mathrm{A}, \mathrm{B}, \mathrm{C}, \mathrm{D}, \mathrm{E}, \mathrm{F}\}$, and are calculating the $S$ - score for States $i$ and $j$ using their mutual relationships with these six third-party states $5^{5}$ State $A$, for example, scores a 1 for its relationship with both State $i$ and State $j$. State $C$ scores a 4 with State $i$ and a 1 with State $j$.

Because $S$ measures the symmetry of common relationships, all points on the diagonal - States $D, A$, and $B$ - represent the same contribution to the $S$-score of dyad $\{i, j\}$. Because all points on the diagonal are perfectly symmetrical, they also represent the maximum contribution for any individual third-party relationship. For all points off the diagonal, as with States $E, F$, and $C$, each point's contribution to the $S$-score is the horizontal (or vertical) distance from the point to the diagonal, illustrated by the red dashed line. Essentially, any point on the diagonal contributes to perfect similarity while points off the diagonal reduce the similarity score.

\footnotetext{
${ }^{2}$ In practice, $w$ is either uniform or corresponds to the Correlates of War's Composite Index of National Capabilities (CINC) score. If we have uniform weighting, $w_{k}$ equals $\frac{1}{n}$. In the case where $w$ corresponds to the CINC score, $w_{k}$ equals State $k$ 's CINC score in the given year for which $S$ is being calculated.

${ }^{3}$ In practice, $L$ is not used because alliances, which are integer values typically not reaching a value higher than 4 , are quite easy to work with.

${ }^{4} S$ is shown to be identical to a textbook example of structural equivalence in the Appendix.

${ }^{5}$ This figure depicts $S$ in the case of uniform weights, no weights, or when the weights are state and not dyad specific.
} 


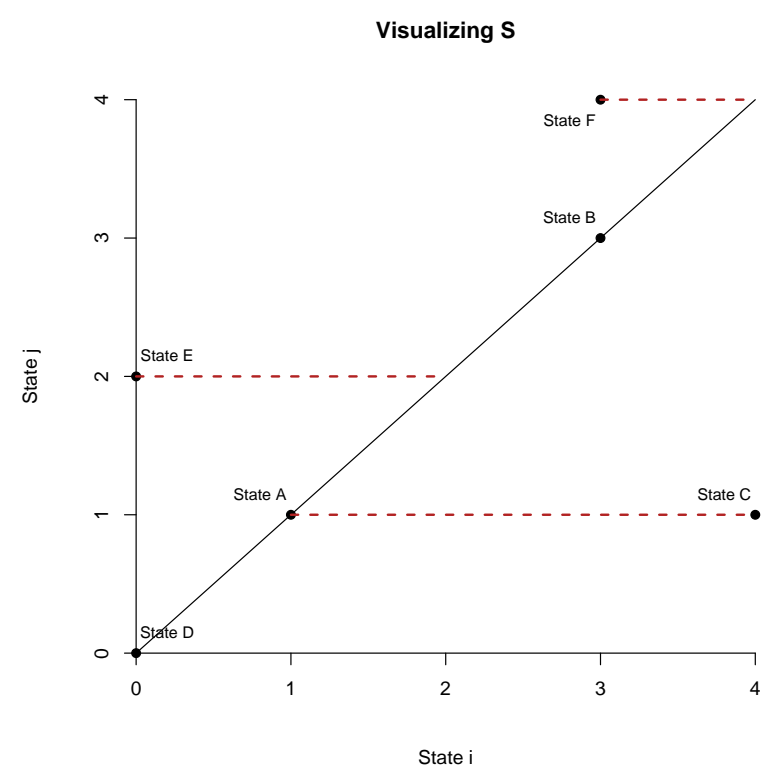

Figure 1: Visualizing S

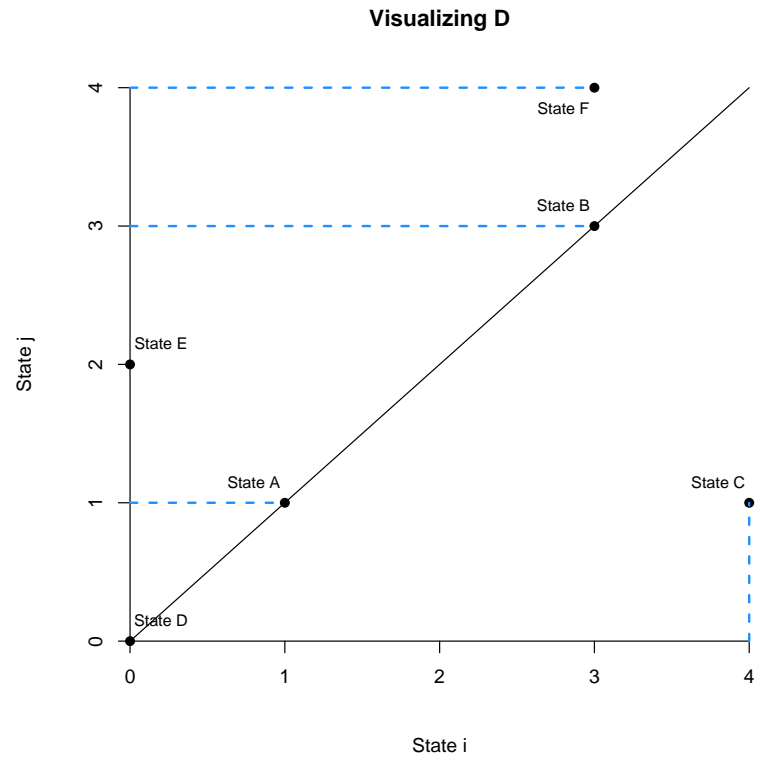

Figure 2: Visualizing D

The disconnect between the operationalization of our measure of foreign policy similarity and our conceptualization of foreign policy similarity can be easily highlighted with a couple examples from Figure 1. To better highlight the differences, assume the points represent an alliance category from the Alliance Treaty Obligations and Provisions (ATOP) dataset (Leeds et al., 2002). According to this schema, 1 equals a non-aggression pact, 2 equals neutrality agreement, 3 equals a defensive alliance, and 4 equals an offensive alliance.

First, compare the different effects of States $F$ and $D$. Because the relationship is not symmetrical, State $F$ will act to reduce the foreign policy similarity of States $i$ and $j$ while State $D$, because the relationship is symmetrical, contributes to perfect similarity. By not incorporating magnitude into the measure we disregard the fact that State $i$ maintains a defense pact with State $F$ and State $j$ maintains an offensive alliance with State $F$ - both indicative of strong preferences.

Second, compare the effects of States $D, A$, and $B$ on the measure of foreign policy similarity. Each relationship with States $i$ and $j$ is symmetrical and therefore falls on the diagonal. Because each relationship is symmetrical, all contribute identically to perfect similarity. This is the case despite the fact that States $i$ and $j$ have no relationship with $D$ and a defense pact with $B$. Once again, a defense pact is indicative of a strong preference but, by not incorporating magnitude, the $S-$ score does not reflect this. 
A more appropriate measure of foreign policy similarity should not only incorporate symmetrical relationships but also the magnitude of the third-party tie. For instance, as states move further away from the origin along the diagonal, they should contribute more: State $B>$ State $A>$ State $D$. Holding symmetry constant, a greater degree of magnitude reveals a stronger preference.

When symmetry is not present, as with State $F$, incorporating magnitude is more subjective. How much should the similarity score be reduced for the off-diagonal component? Mathematically, there are many ways to combine magnitude and symmetry to reflect a single value for the mutual relationship. While the best approach is therefore debatable, a conservative estimate is to use the weak link assumption, which is to say that the contribution to the overall score is the lesser of the two relationships with the third party.

The $D$ algorithm incorporates these principles and is shown visually in Figure 2, For all points that fall above the diagonal, that point's contribution equals the horizontal distance from the point to the Y-axis (e.g., State $F$ ). For all points below the diagonal, the contribution equals the vertical distance to the $\mathrm{X}$-axis (e.g., State $C$ ). For all points on the diagonal, the contribution equals either the horizontal distance to the $\mathrm{Y}$-axis or the vertical distance to the $\mathrm{X}$-axis (here shown as the horizontal distance for States $A$ and $B)$.

As can be seen in the dashed lines in Figures 1 and 2, which represent the contribution to the scores from each third-party, $S$ and $D$ are structurally different. For example, States $F$ and $B$ contribute quite differently depending on which measure is used. $S$ is not a measure of magnitude, and so State $B$ has the same contribution as States $A$ and $D$. Using $D$, both States $F$ and $B$ contribute the same amount to the measure of policy similarity; a contribution which is larger than that of other states.

Formally, the calculation of $D$ is straightforward:

$$
D\left(p_{i}, p_{j}\right)=\sum_{k=1}^{n} \min \left(p_{i k}, p_{j k}\right)
$$

Since some states will cooperate with many while other states will cooperate with none, this variable is heavily skewed. In the subsequent analysis, $D$ is normalized to range from 0 to 1 . Specifically, all scores are normalized by the maximum observed similarity in a given year. This allows for the similarity score to adapt to a changing international environment where the degree 
of similarity in the 1980s might be very different from the similarity we observe today. Thus, the $D$ - score is a relative measure that considers the types of cooperation prevalent at the time.

$$
D\left(p_{i}, p_{j}\right)=\frac{\sum_{k=1}^{n} \min \left(p_{i k}, p_{j k}\right)}{\max \left(D_{\text {year }}\right)}
$$

Hage (2011) proposes to apply Scott's $\pi$ and Cohen's $\kappa$, two statistics that incorporate chance correction to the measurement of foreign policy similarity ${ }^{6}$ Chance correction allows for the possibility that both states will have a mutual relationship with a third-party by chance. This is called a chance agreement. More specifically, if the foreign policy portfolios were randomized, a chance agreement occurs when both states randomly have an identical policy towards a third-party (Gwet, 2002). Given the sparsity of foreign policy portfolios, chance correction mostly applies to the non-existent third-party relationships.

Although Hage's measures are an improvement over the $S$-score in some applications, they still neglect the degree of mutual relationships. That is, common third-party relationships are equivalent, regardless of the strength of the relationship. Dissimilar but strong third party relationships are still dissimilar and will penalize the foreign policy similarity score. The $D$-score, in contrast, accounts for these shortcomings.

\section{Cooperation and Revealed Preferences}

As specified by Signorino and Ritter (1999), weighting schemes, scoring rules, the distance metric, and the composition of the foreign policy portfolio are all design decisions to be made by the researcher. Bennett and Stam (2000) also suggest a modification to the $S$ - score to incorporate regional and global distinctions. By contrast, the $D-$ score does not have weighting schemes or scoring rules. Because the lack of a relationship (zeros in the policy portfolio) does not artificially inflate the similarity score, it is not necessary to calculate regional versions, as in Bennett and Stam (2000). Furthermore, the algorithm specifies the lesser of two values be used in each pairwise comparison, so there is no decision as to which distance metric is to be used. However, the construction of the $D$ - score does entail one moving part: the foreign policy portfolio.

\footnotetext{
${ }^{6}$ Cohen's $\kappa$ also accounts for the fact that some states will exhibit greater propensities to form alliances than others.
} 
The policy portfolio used to construct measures of foreign policy similarity is typically comprised of just formal alliances. For measuring foreign policy similarity, alliances have their share of shortcomings, including the fact that having no alliance can mean multiple things, states do not always choose to ally, and states value alliances with other states differently (Wagner, 1984; Bennett and Rupert, 2003; Sweeney and Keshk, 2005, Li, 2005; Fearon, 1997; Morrow, 2000). Specifically, from 1971-2001 there are 428,015 dyad-years in the data and 399,071 have no alliance.7 Of these, the "no alliance" category includes "those that have no alliance with each other because they are hostile to each other, those that have no alliance because they are irrelevant to each others security, and those that have no alliance because of implicit alignment that renders a formal treaty unnecessary" (Signorino and Ritter, 1999, p. 123). Each of these relationships appear identical if our sole indicator is alliances.

In what follows, alliances are considered to be one indicator of a dyad's latent level of military cooperation. Other indicators include joint military exercises, arms transfers, and multinational peacekeeping and combat operations. Each of these four indicators plus alliances are combined to estimate military cooperation via the graded response model (GRM) (Samejima, 1997).

\section{Policy Portfolio Data}

Military cooperation is defined to take place when a policy is adopted by two or more states for the purposes of either (1) reducing one or more excluded state's military power, (2) enhancing the military power of at least one state, or (3) coordinating military activity for the benefit of some state or set of states. The policy must deliberately involve a military in some capacity, and may be either behavioral or institutional. Table 1 provides a categorization for the indicators used in this study based on this definition of military cooperation.

At the dyadic level, military cooperation is an underlying, latent and continuous concept that manifests in observable ways. Each of these manifestations is an indicator of military cooperation. The five indicators used in the foreign policy portfolio are briefly discussed below.

\footnotetext{
${ }^{7}$ These numbers are calculated using the COW alliance data and state-system membership.
} 


\section{Table 1: Indicators of Military Cooperation}

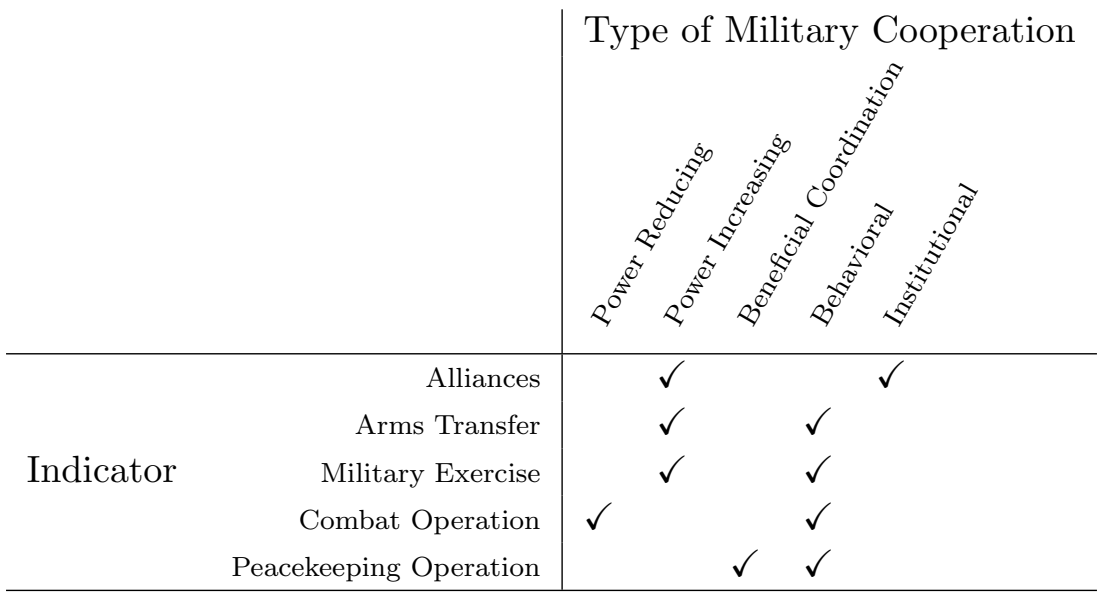

Note: These are general categorizations for indicators of military cooperation. They are not mutually exclusive.

\section{Alliances}

Despite their granularity, alliances are a significant indicator of military cooperation. Leeds et al. (2002) define alliances as "written agreements, signed by official representatives of at least two independent states, that include promises to aid a partner in the event of military conflict, to remain neutral in the event of conflict, to refrain from military conflict with one another, or to consult/cooperate in the event of international crises that create a potential for military conflict" (p. 238). In essence, alliances are a pledge to act in a certain way in the event of war.

Alliances can signal various depths of cooperation, depending on the actions that a state pledges to take in the event of war. The Correlates of War data, which is used here, defines three types of alliances, which are ordered in terms of the depth of cooperation entailed (Gibler and Sarkees 2004; Gibler, 2009). A defensive alliance, which signals the deepest cooperation, requires signatories to come to the defense of one another should one be attacked. Non-aggression and neutrality agreements are each coded at the middle level of cooperation, but they are also slightly different from one another. A non-aggression pact ensures that the signatories will not declare war on one another while a neutrality pact requires states to at least remain neutral in the event of war. Finally, an entente is a pledge to consult one another should a conflict emerge. Here, an entente is coded as the weakest form of alliance. 


\section{Arms Transfers}

Similar to an alliance, arms transfers are a security-enhancing indicator of military cooperation. They, too, reveal a depth of cooperation, both in the simple decision to deal arms to a state as well as in the amount of arms dealt to a state. As such, arms transfers are more than just sale for profit. They are a strategic policy option meant to shore up a relationship.

Data on arms transfers is made available by the Stockholm International Peace Research Institute (SIPRI). For every year, the value of the arms transfer is scored using SIPRI's trend indicator value (TIV). The TIV is SIPRI's valuation of the arms transfer based in constant 1990 U.S. dollars. According to Dr. Holtom, "SIPRI TIV are best used as the raw data for calculating trends in international arms transfers over periods of time, global percentages for suppliers and recipients, and percentages for the volume of transfers to or from particular states" (personal communication, December 9,2011). As a result, the TIV is a continuous variable and it is assumed that the greater the value of the arms transfers, the greater the depth of cooperation.

\section{Joint Military Exercises}

A third type of military cooperation comes in the form of joint military exercises (JMEs). JMEs, or war games, take place when the militaries from more than one state interact in such a way as to enhance their ability to carry out military operations. Although they have a wide range of practical purposes, JMEs also have political implications ranging from boosting a state's status to disguising military buildups. Different types of exercises serve different purposes: some are meant to signal a commitment or a willingness to get involved in a conflict or to deter states from further escalations towards conflict, and others may be held primarily as a coordination exercise among members of the same international organization.

JMEs enhance the security of participating states by improving the military's ability to carry out military operations. Data on JMEs are from D'Orazio (2013). Although different types of exercises reveal different levels of cooperation, the current JME data have not coded the magnitude of the exercise. Therefore, depth of cooperation for this indicator is measured by the number of JMEs a dyad participates in for a given year. 


\section{Multinational Military Operations}

A fourth type of military cooperation comes in the form of multinational military operations. Within this category are both combat and peacekeeping operations. Similar to a military exercise, these are behavioral forms of cooperation. In the case of combat operations, multiple states are cooperating to reduce the security of another state by carrying out a military operation against that state. In the case of peacekeeping operations, multiples states are promoting the security of another state by executing a military operation designed to maintain or enforce peace.

The multinational combat operations indicator has been constructed using PRIO's armed conflict data (Themnér and Wallensteen, 2014). All cases of more than one state fighting on the same side of an issue are coded as those states cooperating in a combat operation. The MID data present another option for operationalizing the multinational combat operations indicator (Palmer et al. 2015). Although the MID data are less restrictive than the PRIO data because they do not require battle-deaths to have occurred, they are not used here because the PRIO data contain both international and intra-state conflict.

The peacekeeping data have been coded from the set of peacekeeping operations that have been labeled by Mark Mullenbach as part of the Dynamic Analysis of Dispute Management project 8 These data include both state-led and organization-led operations, but are limited to to peacekeeping operations in intra-state conflicts. Although there are other mechanisms for capturing the level of participation by a state in a given multinational military operation, here the depth of cooperation is measured by the number of joint operations in a given year.

\section{Other Indicators of Military Cooperation}

Other indicators of military cooperation could also be included when measuring this concept. Additional behavioral indicators include military aid, some specific types of sanctions, and international military education. Additional structural indicators could include membership in regional security institutions, such as the Shanghai Cooperation Organization, and general defense cooperation and information security agreements (Kinne, 2012). As more data become available, the construction of the policy portfolio should incorporate the theoretically relevant indicators.

\footnotetext{
${ }^{8}$ The universe of observations as well as other information pertaining to this project is available at http://uca. edu/politicalscience/dadm-project/
} 


\section{The Military Cooperation Estimate}

The $S$ algorithm incorporates multiple policies by constructing an additive index from each policy, which means that all policies are assumed to be of equal weight and a one-unit increase in one policy is identical to a one-unit increase in any other. Furthermore, it also assumes that increases of x-units on any individual policy are identical regardless of where the increase takes place.

Rather than assuming each indicator is weighted the same, the GRM estimates the effect of the latent trait on the indicators with respect to one another. Low levels of military cooperation, for example, might result in an observed multinational peacekeeping operation but not in a multinational combat operation, which may be reserved for those observations with a high level of military cooperation. For the GRM, the effects of increases within an indicator are also estimated as a function of the latent trait so that an x-unit change in the indicator does not always correspond with a y-unit change in the estimate of military cooperation. Instead, the effect is determined by where the $\mathrm{x}$-unit change in the indicator occurred. For example, the decision to move from 0 to 1 military exercise should influence the measure of military cooperation more than a move from 4 to 5 JMEs 9

Formally, each dyad-year is indexed by $i=1, \ldots, n$. The indicators of military cooperation are represented by $j=1, \ldots, m$ and the set of ordinal responses for each $j$ is given by $k=1, \ldots, K_{j}$. The following model is estimated using the grm function in the ltm package in R (Rizopoulos, 2006).

$$
\begin{aligned}
P\left(y_{i j}=k \mid x_{i}\right) & =g\left(\eta_{j k}\right)-g\left(\eta_{j, k+1}\right), \\
\eta_{j k} & =\alpha_{j}\left(x_{i}-\beta_{j k}\right), k=1, \ldots, K_{j}, \\
g(z) & =\frac{1}{1+e^{-z}}
\end{aligned}
$$

The main component in the model for ordinal response data is the probability of the $i$ th dyad-year

\footnotetext{
${ }^{9}$ For the GRM, the item responses are assumed to be ordinal, which is the case with each of the five indicators except for arms transfers. The arms transfer data, SIPRI's trend indicator value, is continuous. Therefore, it has been scaled to represent five levels of arms transfer. The first is a level of 0 where no arms transfer has occurred. The vast majority of dyad-years - 509,253 out of 519,887 - fall into this category. The remaining 10,635 dyad-years are split roughly evenly into the four levels, with 2,620 in the first, 2,659 in the second, 2,681 in the third, and 2,674 in the fourth. Similarly, the joint military exercises and peacekeeping indicators range from zero to twelve and zero to sixteen, respectively. For ease of interpretation, these indicators are scaled to range from zero to eight. For each, 7 and 8 receive a score of 7 while 9 and higher receive a score of 8 .
} 
to reach the $k$ th level of military cooperation for the $j$ th indicator $\left(y_{i j}\right)$, given the latent level of military cooperation for the dyad-year $\left(x_{i}\right) . \beta_{j k}$ are the extremity parameters and $\alpha_{j}$ are the discrimination parameters, both of which are of interest for assessing the model's performance.

Treier and Jackman (2008) use a similar method for calculating a regime-type measure using the Polity indicators, and Benson and Clinton (2012) use an application of item response theory to measure the strength of an alliance across two dimensions: the power of the individual states that are party to the agreement and the terms of the agreement itself.

\section{Model Exploration}

Table 2 shows the estimates of the GRM 10 With respect to the extremity parameters, shifts that are particularly large or small indicate the different effects of increases on any particular indicator. Here, the intervals between the estimates are not uniform, although there is considerable variation in them. Alliances are all nearly identical, which suggests that alliance categories mean little, but rather what is important is the presence of an alliance. Joint military exercises appear to have a particularly strong effect at their first interval, suggesting that the initial decision to hold a military exercise is most valuable, but smaller subsequent effects. Another notable shift is the steady increase in the values on the arms transfers scale. This suggests that a one-unit increase in the arms transfers scale has the weaker effect at low levels than at high levels. In a sense, this provides within-indicator evidence that additive scaling is not appropriate and a GRM is providing a more accurate expression of the latent trait.

The discrimination parameter represents the slope on the item characteristic curves, the basic units of an IRT model that take the shape of logistic functions. These parameters express the indicator's ability to estimate some latent level of military cooperation. The lower the number, the flatter the curve and the less ability the item has to discriminate among values of the latent trait. A steeper slope demonstrates an item's increased ability to discriminate between values of the latent trait that correspond to the location where the slope is steepest.

Alliances discriminate best while each other indicator discriminates more or less evenly-well. Alliances do best because they are the only indicator that discriminates the dyad-years for lower levels of military cooperation. All the others are only valuable at differentiating dyad-years for

\footnotetext{
${ }^{10}$ The estimates in Table 2 have confidence intervals that are not reported.
} 
Table 2: GRM Parameter Estimates

\begin{tabular}{|c|c|c|}
\hline Indicators & Discrimination & Extremity \\
\hline \multirow{3}{*}{ Alliance Level } & \multirow{3}{*}{-3.319} & -1.856 \\
\hline & & -1.868 \\
\hline & & -1.873 \\
\hline \multirow{8}{*}{ Joint Military Exercises } & \multirow{8}{*}{-1.587} & -3.341 \\
\hline & & -4.140 \\
\hline & & -4.573 \\
\hline & & -4.896 \\
\hline & & -5.187 \\
\hline & & -5.490 \\
\hline & & -5.846 \\
\hline & & -6.371 \\
\hline \multirow{4}{*}{ Arms Transfers } & \multirow{4}{*}{-1.488} & -3.006 \\
\hline & & -3.257 \\
\hline & & -3.589 \\
\hline & & -4.117 \\
\hline \multirow{8}{*}{ Peacekeeping Operations } & \multirow{8}{*}{-1.481} & -2.481 \\
\hline & & -2.863 \\
\hline & & -3.230 \\
\hline & & -3.549 \\
\hline & & -3.875 \\
\hline & & -4.201 \\
\hline & & -4.558 \\
\hline & & -5.217 \\
\hline \multirow{4}{*}{ Combat Operations } & \multirow{4}{*}{-1.393} & -4.263 \\
\hline & & -5.354 \\
\hline & & -5.966 \\
\hline & & -6.682 \\
\hline
\end{tabular}

higher levels of military cooperation.

The model estimates a dyad's latent level of military cooperation for a given year. In comparison to alliances, this estimate provides a more complete measure of the underlying dyadic relationship necessary to measure foreign policy similarity. To provide some face validity for this measure, therefore, it is compared with alliance data for the United States. To do so, three alliance categories are subset from the data: no alliance, an entente, neutrality, or non-aggression pact, and defense pacts. Each of these three types are further split into three decades: 1971-80, 1981-90, and 19912000.

For each decade and for each alliance type, the estimate of military cooperation with the United States for a state in a given year is placed on a scale from one to twenty. This scale is divided into equal parts based on the range of possible estimates of military cooperation. Although twenty is an arbitrary number, the distributions in Figure 3 serve the primary point.

Figure 3 demonstrates that considerable variation within alliance categories exists for many of 
1971-1980

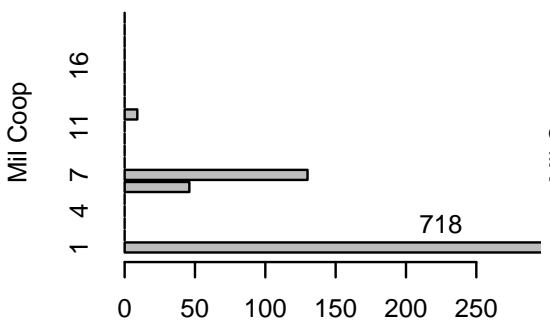

Number of State-Years

1971-1980

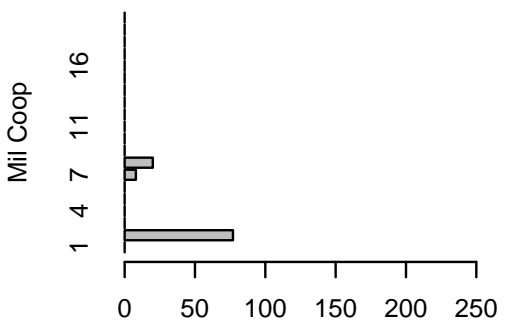

Number of State-Years

1971-1980

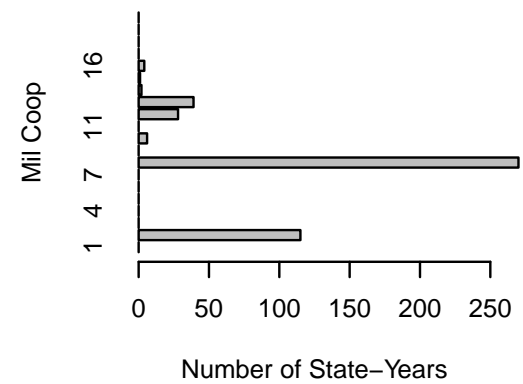

No Alliance

1981-1990

1991-2000

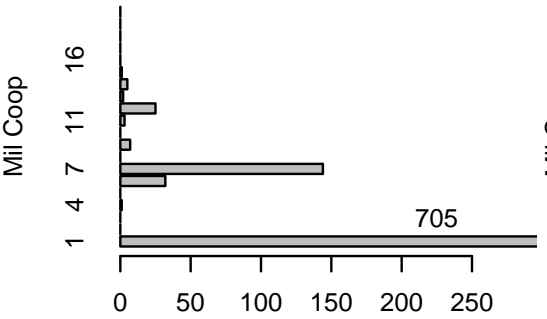

Number of State-Years

Nonaggression Pact

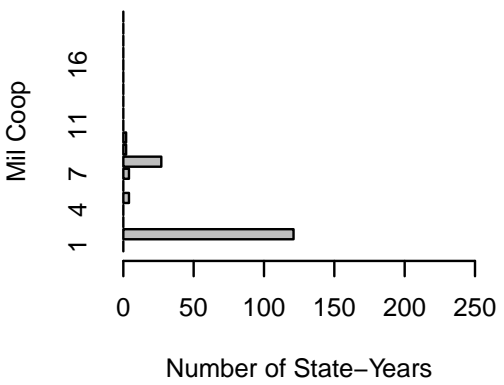

Defense Pact

1981-1990

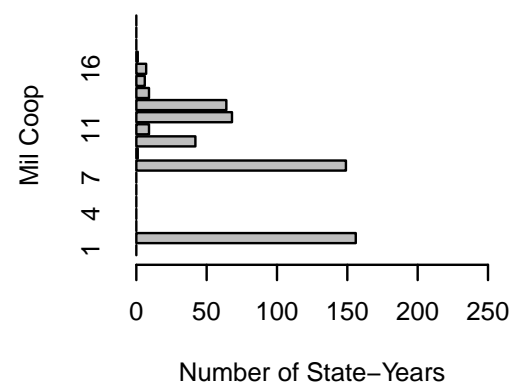

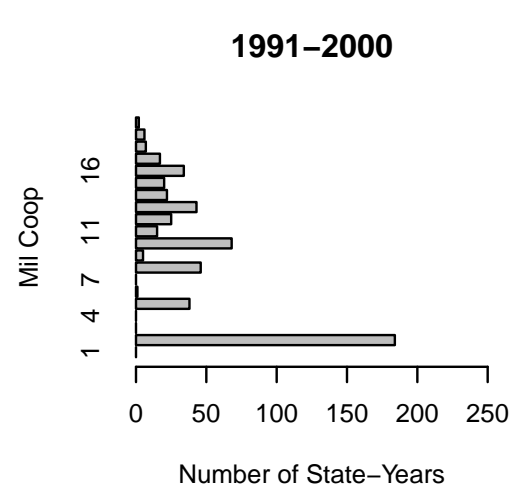

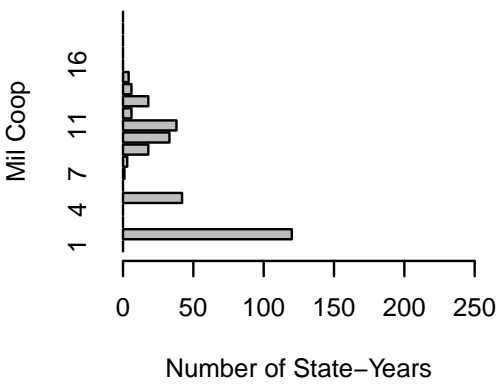

1991-2000

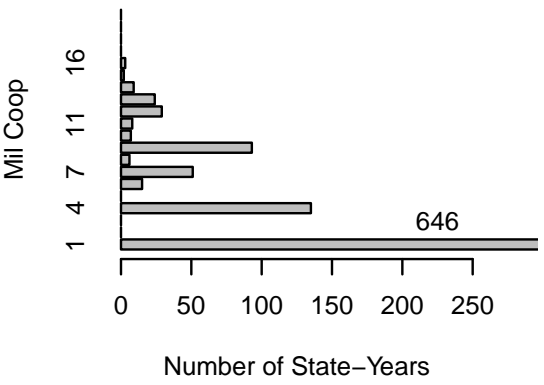

1991-2000

Figure 3: United States 
the dyad-years in the data. Additionally, there are two important trends to point out. First, the variance within any alliance category is increasing over time. This is seen by the increasing skew of the distribution that is observed in each of the alliance types as one moves across decades. This means that states are increasingly engaging in more types of military cooperation with the United States than they have in the past. Second, there is variation across alliance categories. There are many states that the United States cooperates with but does not have an alliance with. Israel is the most commonly used example of such a relationship. In other cases, a defense pact is present, but no other indicator of military cooperation is present. This is represented by the lowest bar in each of the three Defense Pact plots in Figure 3.

The granularity of alliance data make it inappropriate to use as the sole indicator of revealed foreign policy preferences. Other forms of military cooperation are indicative of those same preferences and may be used as part of a state's policy portfolio. Their incorporation into a measure of foreign policy similarity, however, ought to be as thoughtful as their inclusion into the policy portfolio. Simple additive indexing is an assumption-laden approach, and better methodologies for combining indicators exist. The GRM is one such method, but certainly others exist and may even provide more intuitive estimates.

Thus far I have suggested a new algorithm for calculating foreign policy similarity and a new approach towards the foreign policy portfolio. The following section compares the resulting $D-$ score to the $S$ - score and to Hage's measures.

\section{Empirical Comparisons}

There are four mainstream $S$ - scores: unweighted global, weighted global, unweighted regional, and weighted regional 11 The distributions of these scores are shown in Figure 4.

Theoretically, the $S$-score ranges from -1 to 1. Empirically, however, the range depends largely on the choice of which $S$-score is used. The unweighted global score ranges from 0.056 to 1 , with the majority of observations scored greater than 0.5 . The weighted global $S-$ score ranges from -0.525 to 1 , but again the vast majority of mass is at or greater than a score of 0.5 . Although the range of the distribution of the weighted regional $S$ - score is from -0.984 to 1 , by far most of these

\footnotetext{
${ }^{11}$ These $S$-scores have been generated with EUGene, and are available through 2000 (Bennett and Stam, 2000). The estimates of military cooperation begin in 1971, and so the overlapping period is 1971 through 2000.
} 

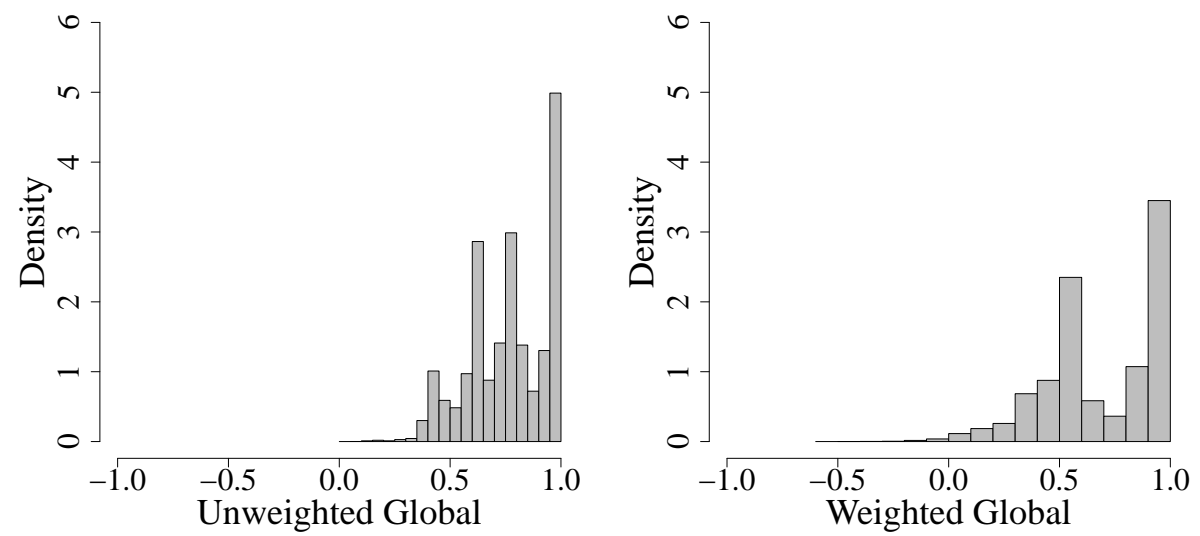

Figure 4: S-Scores: $1971-2000$

observations are scored at or near a perfect similarity score of 1 . The unweighted regional score, which has a range of -0.984 to 1 and contains significant mass at both ends of that spectrum, is perhaps more reasonable given our expectations of foreign policy similarity, but there still appears to be many dyad-years that are extremely similar.

Figures 4 and 5 appears so skewed because of the many relationships in the international system that are symmetrical due to the lack of a relationship. Hage (2011) proposes to use Cohen's $\kappa$ or Scott's $\pi$ to account for this sparsity. As shown in Figure 6, the distribution of Hage's two measures are similar to each other and quite different from the $S$ - scores. For example, instead of having the most mass at -1 or 1 , they have the most mass at 0 . It is interesting that there is so little mass from scores of about 0.1 up until 1, and then significant numbers of observations at 1. Specifically, there are 42,073 observations of 1 out of a total 409,872 observations in the data. Upon closer look, these states are mostly those of NATO and the OAS, although there are other dyads in there as well. It is a feature of these chance-corrected methods that several dyads will be coded at perfect similarity. By construction, the $D-$ score is different.

For the $D$-score, most observations are scored at or near 0 and there is a long tail to the distribution.

Thus far I have argued that the method proposed here improves both on previous algorithms and on previous foreign policy portfolio constructions. To demonstrate the differences in $D$ and $S$ for foreign policy similarity, both scores are plotted side by side with one another using the estimated military cooperation as input and alliances as input. 

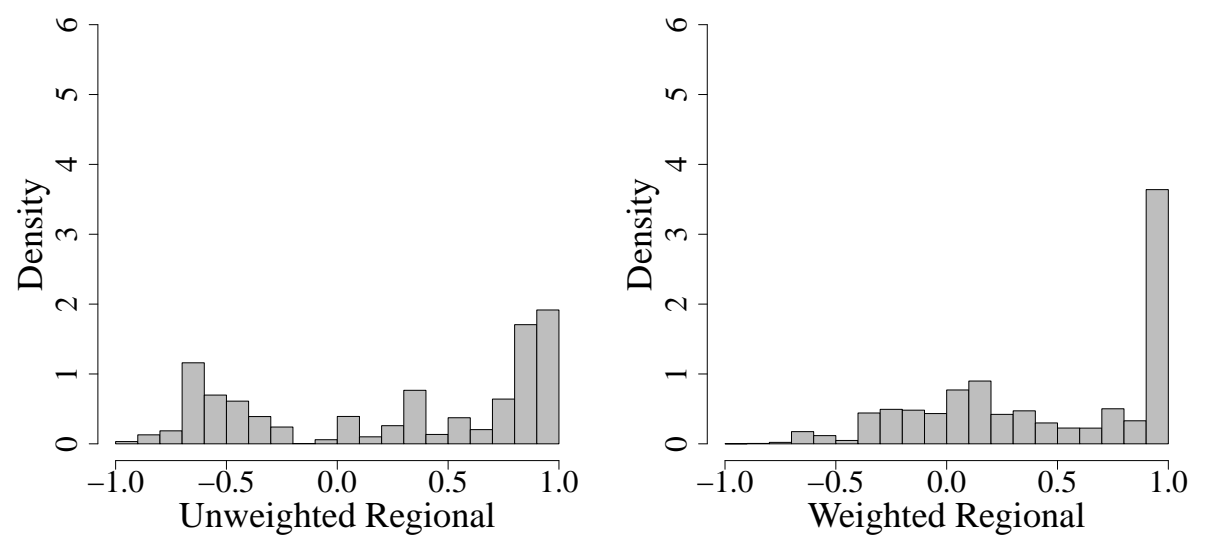

Figure 5: S-Scores: $1971-2000$
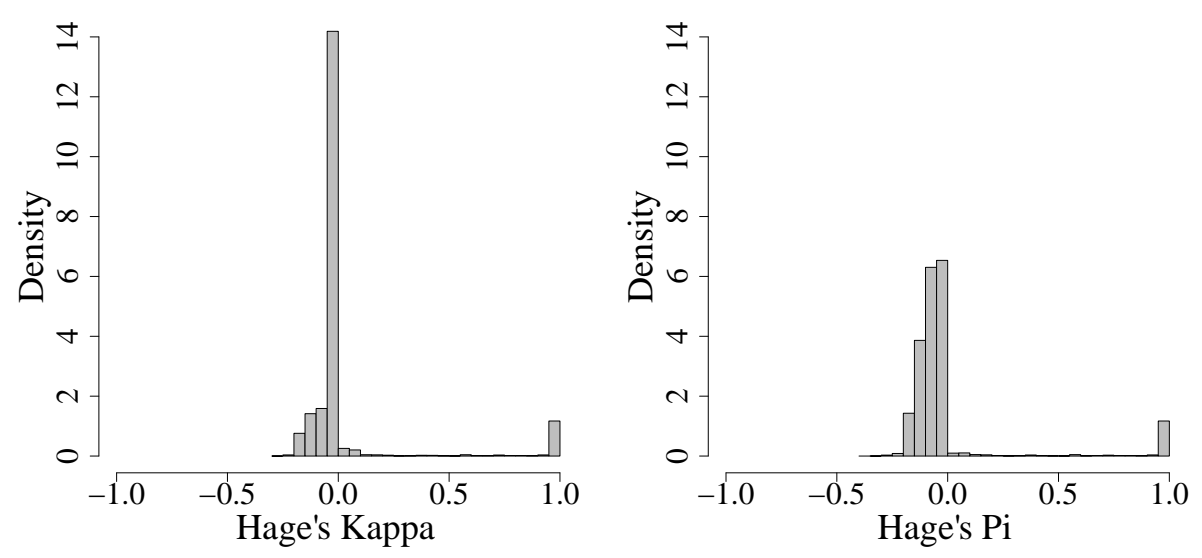

Figure 6: Hage's Kappa and Pi: 1971 - 2000
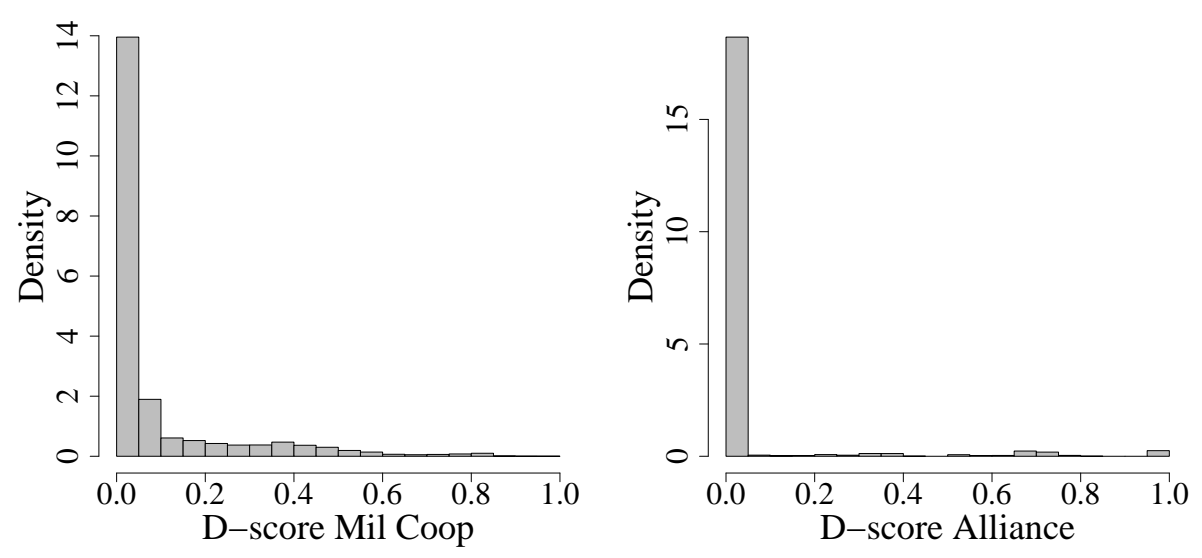

Figure 7: The D-Score: $1971-2000$ 
The first set of plots are the $D$ and $S$ scores using military cooperation and alliances for the United States with Great Britain, India, Israel, Argentina, Russia, and Mexico from 1971 through 2000. Holding the algorithms constant, the construction of the foreign policy portfolio by estimating military cooperation as a latent trait adds considerable variation to the measure. This is highlighted in the difference when moving from the bottom row of figures to the top. Similarly, there is added variation depending on the algorithm. This is highlighted when moving from the right column (the $S$ algorithm) to the left column (the $D$ algorithm).

The first case to point out is the difference in Argentina's and the UK's foreign policy similarity with the US. The UK and Argentina went to war in 1982 over the disputed Falkland Islands and the world was curious with whom the US would side. Eventually, the United States supported the UK with military equipment but did not directly intervene. Figure 9, which uses alliances as input data, clearly play Argentina above the UK, suggesting the US would have sided with Argentina. Figure 8, which uses military cooperation, shows a much closer estimate of foreign policy similarity. When coupling the $S$ algorithm with military cooperation, Argentina is narrowly above the UK, again suggesting that the US is more likely to side with Argentina. However, when using the $D$ algorithm, the UK is above Argentina in terms of foreign policy similarity.

The divergence of Mexico and Argentina beginning in the late 1980s in Figure 8 is also consistent with history. Despite both being members of the Organization of American States, which means they have a similar set of alliances, Mexico has not integrated its foreign policies the same way that Argentina has. Argentina is active in peacekeeping operations, joint military exercises, and multinational combat operations. Generally speaking, Argentina is a regular for military cooperation with the states of Western Europe. Mexico, on the other hand, is largely preoccupied with domestic concerns and has not taken its military to the international system in the same way that Argentina has.

Other states also reflect history more accurately in with the $D$-score and military cooperation. For example, there is an increase in foreign policy similarity beginning around 1990 with respect to Russia and India, which should not come as a surprise considering the way the international system has changed since the end of the Cold War. Military cooperation in particular has been increasing, and it should therefore be expected that a measure of security policy similarity reflect such increases. 
United States: 1971-2000

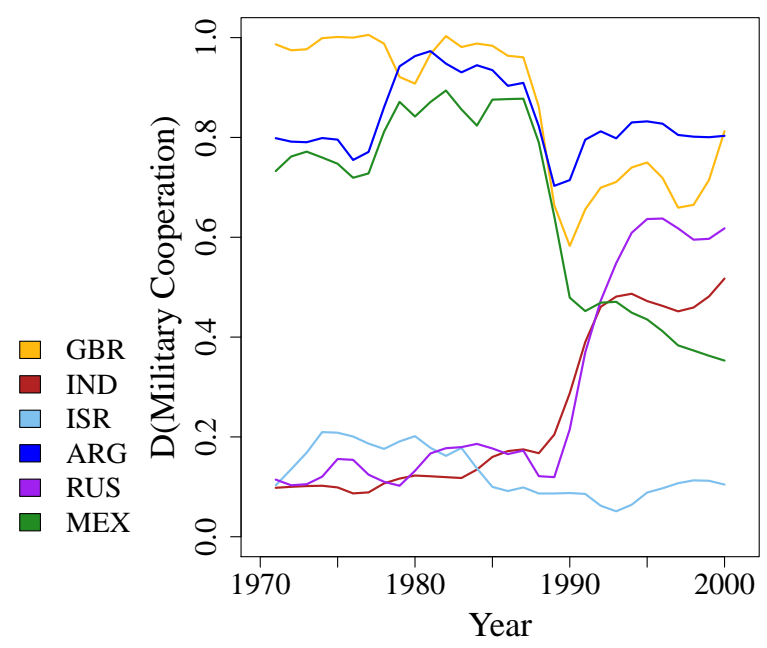

United States: 1971-2000

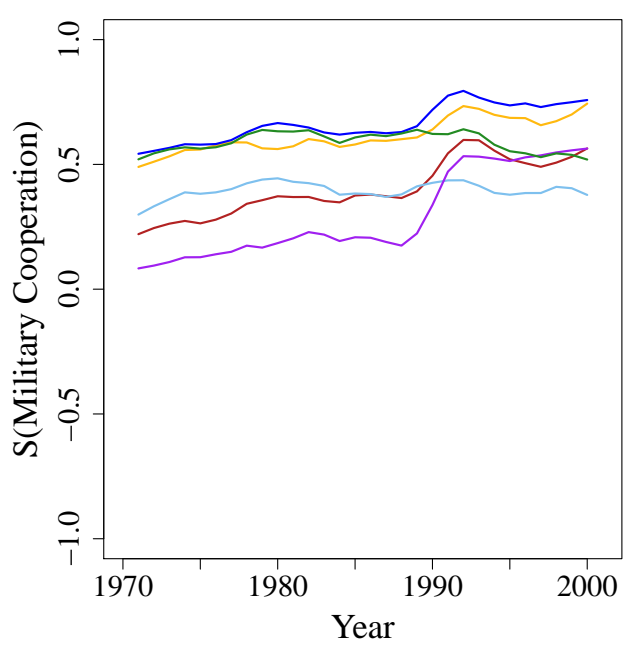

Figure 8: D-Score and S-Score with Military Cooperation Data

The plots of the $S$-scores demonstrate some of the fundamental issues with using the $S$-score. Specifically, the $S$-score is universally inflated and does not change much over time. The $D$-score, as calculated with alliance data in Figure 9, also does not change much over time. However, the similarity scores with Russia, Israel, and India are all extremely low, which is what one would expect when calculating the foreign policy similarity for states that have very few formal alliances in common. Contrast this to the $S-$ scores scores seen in Figure 9 and another primary difference in the two measures is seen. The $S$ - score inflates these values while the $D-$ score values them at or near zero.

Russia's foreign policy similarity, calculated from 1971-2000 with military cooperation, is plotted for Great Britain, India, Israel, Argentina, the United States, and Poland. The $S-$ score again reflects a largely constant measure while the $D$ - score reveals a different trend; one that is a more appropriate fit for how recent Russian history has unfolded. In Figure 10, the sharp increase in policy similarity after the Cold War is what would be expected for Russia. The United States, United Kingdom, and Poland are the three most similar states in Figure 10, with India and Argentina having a roughly identical similarity to Russia and Israel is again at or near the lowest.

Israel and Poland reflect perhaps the most interesting types of relationships here. For the $D$ - score, whether it be with the United States or Russia, the security policy similarity with Israel is at-or-near the lowest. This reflects the empirical fact that Israel does not cooperate militarily 
United States: 1971-2000

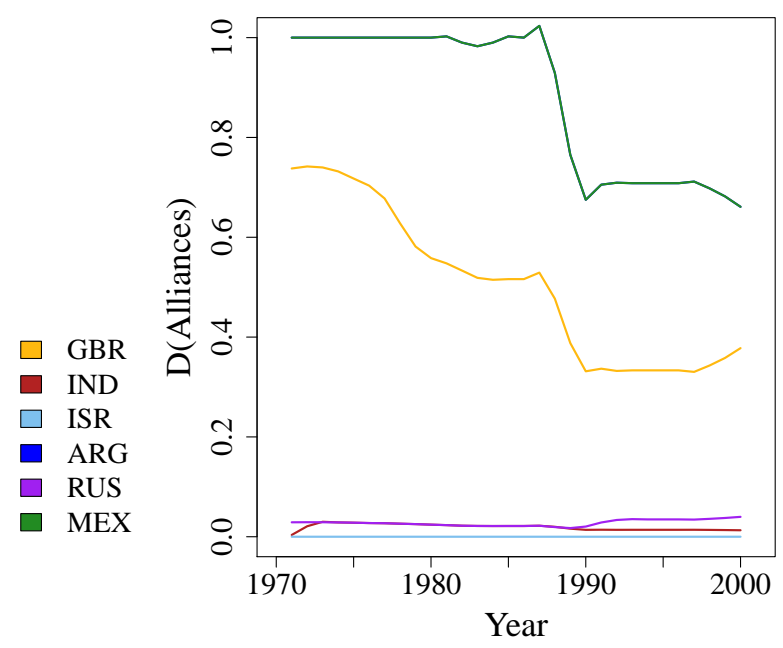

United States: 1971-2000

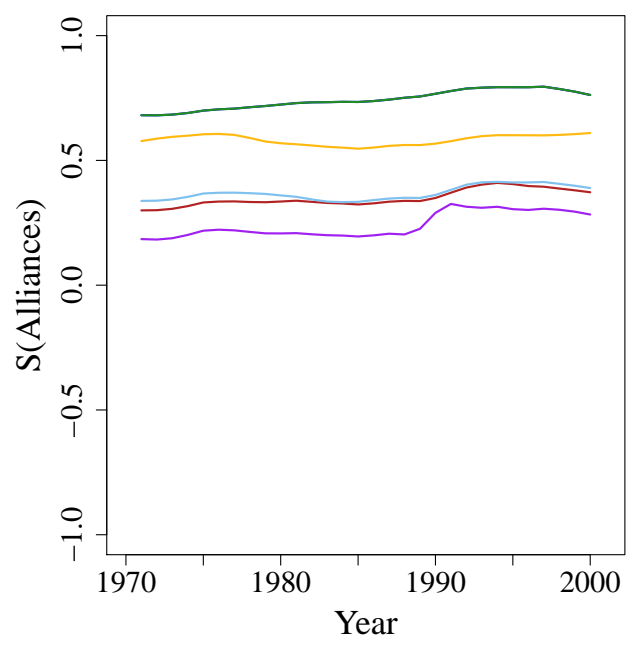

Figure 9: D-Score and S-Score with Alliance Data

with many states; its security policies are considerably more local. Contrast this with the United States, whose security policy is global.

Poland represents another particularly interesting example. During the Cold War, Russia and Poland were close allies with very similar foreign policies. Since the Cold War ended, Poland's foreign policy has been largely in line with Western interests. Poland joined NATO, for example, and was one of just three other states to initially contribute troops to the United States' 2003 invasion of Iraq. The $D$ - score shows a level of policy similarity just below that of the US and UK while the $S$ - score puts Russia and Poland near one.

Figure 11 shows Hage's constructs of foreign policy similarity among Russia and the same set of states. Both measures are very similar, and both capture Russia's relationship with Poland better than either the $D-$ score or the $S$ - score. However, both also fail to capture any meaningful or sustained change in similarity among Russia and either US or UK. Historically, we know that when the Cold War ended Russia moved considerably closer to Western Europe than it had been during the Cold War, and despite a brief increase in similarity around 1990 this is not reflected.

\section{Replications with the S-score, D-score, and Hage's $\kappa$}

Three articles, each of which uses the $S$ - score in different but representative ways, are replicated with both the $D$-score and with Hage's $\kappa$. The inferences drawn from studies using the $S-$ score 

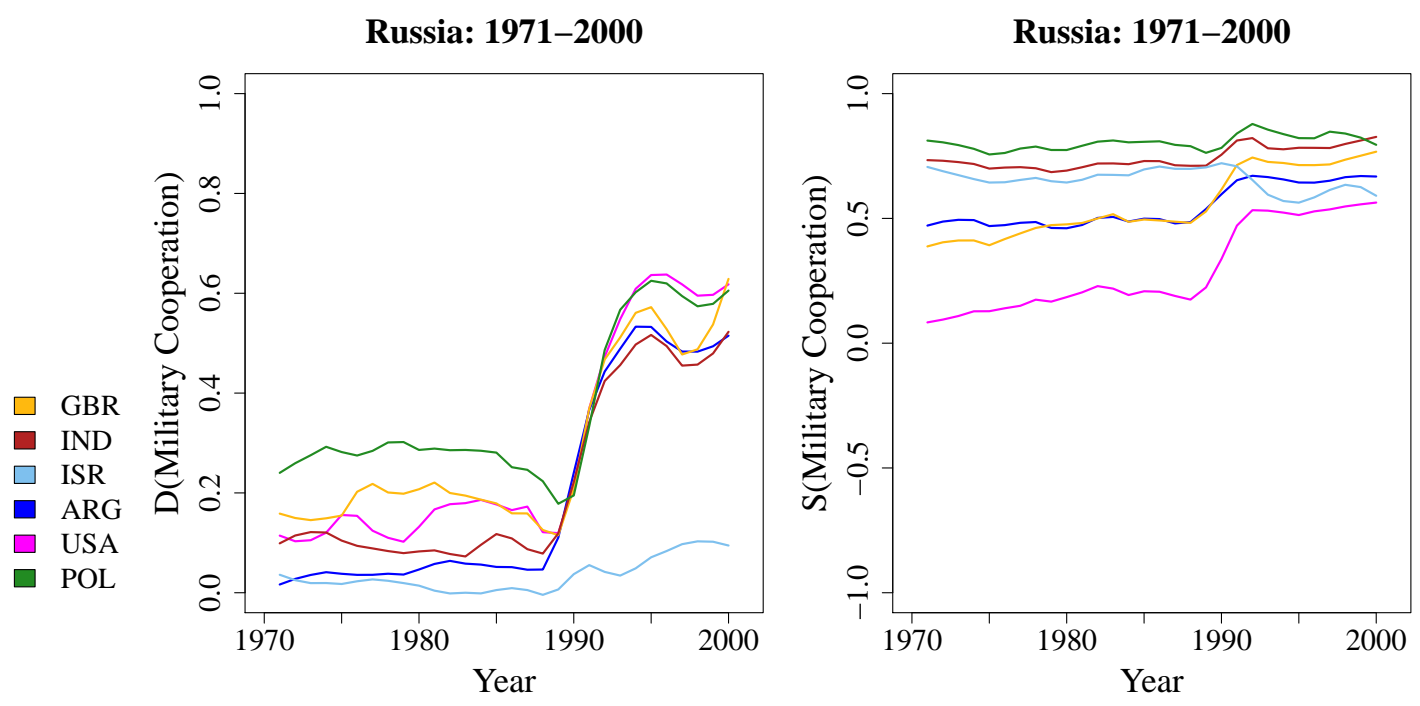

Figure 10: D-Score and S-Score with Military Cooperation Data

are different from the inferences drawn when using the $D$-score or Hage's $\kappa$.

\section{Replication One: Arming the Embargoed}

Moore (2010) is an example of an article that uses $S$ as its main explanatory variable. Moore tests a supply-side theory of arms embargo violations and finds that, provided a state is going to violate an embargo, it will do so to a greater degree with a state that has similar foreign policies to that of the violator. Here, I replicate those results and demonstrate that $S$ and $D$ are not substitutable with one another.

Table 3: Replicating Moore's Table 3

\begin{tabular}{lrrrr}
\hline \hline & Original Results & Replicated & With $D$ & With Kappa \\
\hline$S$ score & $2.670^{* *}(1.189)$ & $2.670^{* *}(1.189)$ & - & - \\
$D$ score & - & - & $-0.019^{*}(0.011)$ & - \\
Hage's $\kappa$ & - & - & - & $16.922^{*}(8.979)$ \\
Constant & $6.144(5.539)$ & $6.144(5.539)$ & $12.020^{* *}(5.375)$ & $-8.743(7.932)$ \\
\hline Observations & 89 & 89 & 89 & 89 \\
\hline
\end{tabular}

Moore's main findings are replicated in Table $3{ }^{12}$ The key finding in Moore $(2010)$ is that $S$ is statistically significant and positive, with the interpretation being that, provided a state is going to violate an arms embargo, it is going to do so to a greater degree with an embargoed state whose foreign policies are similar to that of the violating state. When using the $D-$ score, however, the

\footnotetext{
${ }^{12}$ The full replication is in Table 6 in the Appendix.
} 

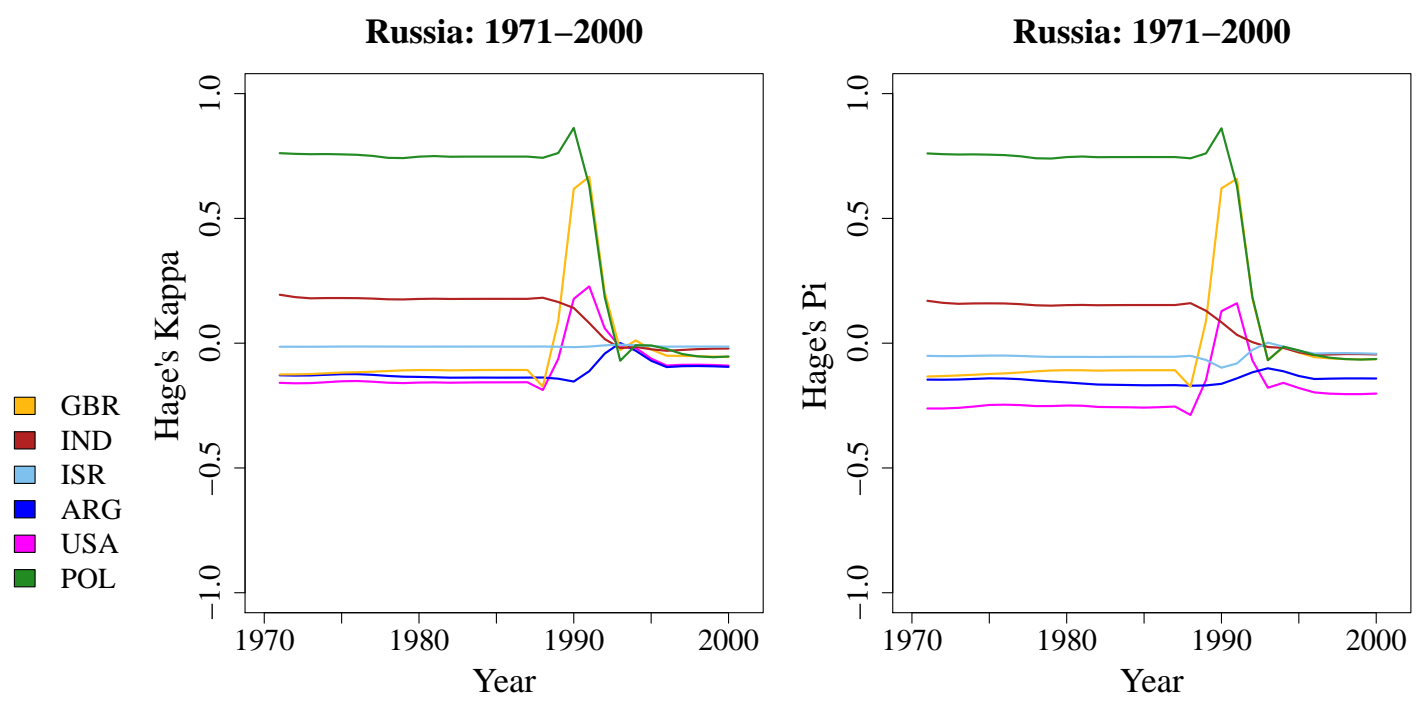

Figure 11: Hage's Kappa and Pi

coefficient is statistically significant and negative. This provides evidence for the exact opposite interpretation and a different view of embargo violators.

By contrast, Hage's $\kappa$ measure supports the original findings when using the $S-$ score. That is, provided a state is going to violate an arms embargo, it will do so with in greater quantities with a state whose foreign policy is similar to its own. The magnitude of the coefficient is much larger for $\kappa$, which may lead to different substantive effects.

\section{Replication Two: To concede or to Resist?}

Fang, Johnson and Leeds (2014) is an example of an article that uses the $S-$ score as a control variable, which is probably its most common application. Here, it is used to control for "the similarity of the two states' interests" (Fang, Johnson and Leeds, 2014, 796). The expectation is that "as this variable increases, the two states' interests are considered to be more similar, and thus they should be less likely to have disagreements that could prompt militarized disputes" (796). This study represents a large number of studies that have used the $S$ - score in this capacity, with this theoretical expectation.

The authors main empirical findings are in their Table 2. They show that formal alliances encourage peace, not just as a deterrent but also thought conflict management effects. This is primarily captured in the Target's cost of damaging its alliance variable. The original results are 
shown in Table 4, along with the same model for the years 1971-2000, or the subset of years that overlap with the data available for the $D$-score and Hage's $\kappa$. As can be seen, the primary empirical finding remains the same across all models: the effect of Target's cost of damaging its alliance is negative and statistically significant. The effect of Challenger-target similarity of interests, however, depends on which operationalization is used.

If the $S$-score is used to operationalize Challenger-target similarity of interests, the coefficient is negative and statistically significant in both the original model and the replication on the 19712000 subset. The $D-$ score, however, is positive and statistically significant. the coefficient on Hage's $\kappa$ is also positive, although it is not statistically significant. Therefore, if either the $D$-score or Hage's $\kappa$ is used, the expectation that dyads with higher levels of foreign policy similarity are "less likely to have disagreements that could prompt militarized disputes" is not supported. This is actually a common justification for using the $S$-score as a control variable and, at least in this application, it is not supported.

Table 4: Replicating Fang, Johnson, and Leeds' Table 2

\begin{tabular}{|c|c|c|c|c|}
\hline & \multirow[b]{2}{*}{ Orig. Results } & \multicolumn{3}{|c|}{ 1971-2000 Subset } \\
\hline & & S-score & D-score & Hage's Kappa \\
\hline \multicolumn{5}{|l|}{ Target Resistance } \\
\hline Target's cost of damaging its alliance & $-.40 * *(.14)$ & $-.83^{*}(.32)$ & $-.77^{*}(.33)$ & $-.78^{*}(.32)$ \\
\hline Constant & $1.63^{* *}(.20)$ & $.98^{*}(.48)$ & $.85(.49)$ & $.92(.48)$ \\
\hline \multicolumn{5}{|l|}{ Dispute Initiation } \\
\hline \multicolumn{5}{|l|}{ Challenger-target similarity of interests: } \\
\hline S-score & $-.51 * *(.05)$ & $-.89 * *(.14)$ & - & - \\
\hline D-score & - & - & $.004^{* *}(.001)$ & - \\
\hline Hage's $\kappa$ & - & - & - & $.06(.06)$ \\
\hline Constant & $1.03^{* *}(.10)$ & $2.17^{* *}(.24)$ & $.77^{* *}(.16)$ & $.94^{* *}(.17)$ \\
\hline Observations & 585,467 & 224,845 & 224,845 & 224,845 \\
\hline Uncensored observations & 1,085 & 267 & 267 & 267 \\
\hline
\end{tabular}

\section{Replication Three: Reliability, Reputation, and Alliance Formation}

The final replication, Crescenzi et al. (2012), uses foreign policy similarity both as a control variable and as input data for the construction of the primary independent variable of interest, alliance reputation.

Table 1, Model 4, whose time period is 1946-2000, provides the closest sample to our data, which ranges from 1971 to 2000. The main finding is that "a reputation for upholding one's agreements significantly improves the likelihood of membership in future alliances" (259). This is shown by the positive and statistically significant coefficient on alliance reputation. 
Table 5: Replicating Crescenzi et al., Table 1, Model 4

\begin{tabular}{|c|c|c|c|c|}
\hline & \multirow[b]{2}{*}{ Orig. Results } & \multicolumn{3}{|c|}{ 1971-2000 Subset } \\
\hline & & S-score & D-score & Hage's Kappa \\
\hline Alliance Reputation: & & & & \\
\hline S-score & $2.82^{* * *}(0.48)$ & $1.32^{* * *}(.16)$ & - & - \\
\hline D-score & - & - & $2.00 * * *(.20)$ & - \\
\hline Hage's $\kappa$ & - & - & - & $2.10^{* * *}(.22)$ \\
\hline Portfolio Similarity: & & & & \\
\hline S-score & $1.30 * * *(0.06)$ & $0.89 * * *(.06)$ & - & - \\
\hline D-score & - & - & $.46^{* * *}(.03)$ & - \\
\hline Hage's $\kappa$ & - & - & - & $.41^{* * *}(.03)$ \\
\hline Constant & $-2.91 * * *(0.05)$ & $-2.45^{* * *}(.06)$ & $-1.77^{* * *}(.02)$ & $-1.84^{* * *}(.02)$ \\
\hline Observations & 842,249 & 618,115 & 617,843 & 618,113 \\
\hline
\end{tabular}

When alliance reputation is calculated using the $D$-score, or using Hage's $\kappa$, the interpretation remains the same: as alliance reputation increases, the likelihood of the dyad forming an alliance also increases. The interpretation for portfolio similarity is also the same: the more similar two states' alliance portfolios, the more likely they are the become allies.

\section{Conclusion}

Foreign policy similarity has been a variable used by students of IR for over thirty years. Altfeld and Bueno de Mesquita (1979) used a network-based approach and made the argument for using alliances as the primary indicator. The resulting measure, $\tau_{b}$, was used to proxy for foreign policy similarity for about 20 years. In 1999, Signorino and Ritter introduced a new algorithm for measuring foreign policy similarity. The $S-$ score retains the network-based approach of $\tau_{b}$ and uses alliances as the primary indicator. However, it is different from $\tau_{b}$ in that it is a measure of similarity while $\tau_{b}$ is not. (Hage, 2011) has introduced the idea of accounting for randomly identical responses, which presents a much more accurate distribution of foreign policy similarity than that of $S$.

In this article I have shown that the method for constructing $S$ is actually a method for measuring structural equivalence, a concept from social network analysis that is used to measure the similarity of positions of two nodes in a network. While potentially of importance to the study of IR, structural equivalence is not how we should be measuring foreign policy similarity because it does not incorporate the magnitude of common relationships, only their symmetry.

A new algorithm for constructing foreign policy similarity, $D$, is introduced. $D$ incorporates the network-based approach of $\tau_{b}$, as well as including aspects of symmetrical relationships into the 
measure. As an improvement upon $S, D$ incorporates the degree of common relationships.

Additionally, instead of relying just on alliances as the sole indicator of foreign policy, the $D$ - score includes multiple indicators of the more general, underlying relationship of military cooperation. By estimating military cooperation as a latent relationship using item response theory, the indicators of military cooperation can be combined into a single measure to then use as input data for the $D$ algorithm.

Each of the measures explored here, the $S$-score, Hage's $\kappa$ and $\pi$ measures, and the $D$-score, have clear differences from one another. This has been evidenced by differences in their theoretical foundations, descriptive comparisons, and by their different effects in a replication study. Moving forward, to better understand which measure to use scholars should precisely define their concepts and select the measure that most accurately reflects such concepts. 


\section{References}

Altfeld, Michael F. and Bruce Bueno de Mesquita. 1979. "Choosing Sides in Wars." International Studies Quarterly 23(1):87-112.

Bapat, Navin A. 2007. "The Internationalization of Terrorist Campaigns." Conflict Management and Peace Science 24(4):265-280.

Bennett, D. Scott and Allan C. Stam. 2000. "EUGene: A Conceptual Manual." International Interactions 26(2):179-204.

Bennett, D. Scott and Matthew C. Rupert. 2003. "Comparing Measures of Political Similarity: An Empirical Comparison of S Versus Tau-b in the Study of International Conflict." Journal of Conflict Resolution 47(3):367-393.

Benson, Brett V. and Joshua D. Clinton. 2012. "Measured Strength: Estimating the Strength of Alliances in the International System, 181-2000." Unpublished manuscript.

Bueno de Mesquita, Bruce. 1975. "Measuring Systemic Polarity." The Journal of Conflict Resolution 19(2):187-216.

Bueno de Mesquita, Bruce. 1981. The War Trap. New Haven, CT: Yale University Press.

Crescenzi, Mark JC, Jacob D Kathman, Katja B Kleinberg and Reed M Wood. 2012. "Reliability, Reputation, and Alliance Formation1." International Studies Quarterly 56(2):259-274.

D’Orazio, Vito. 2013. International Military Cooperation: From Concepts to Constructs PhD thesis Pennsylvania State University.

Fang, Songying, Jesse C Johnson and Brett Ashley Leeds. 2014. "To Concede or to Resist? The Restraining Effect of Military Alliances." International Organization 68(04):775-809.

Fearon, James D. 1997. "Signaling Foreign Policy Interests: Tying Hands Versus Sinking Costs." Journal of Conflict Resolution 41(1):68-90.

Gartzke, Erik. 2007. "The Capitalist Peace.” American Journal of Political Science 51(1):166-191.

Gibler, Douglas M. 2009. International military alliances, 1648-2008. Washington: CQ Press. 
Gibler, Douglas M. and Meredith Sarkees. 2004. "Measuring Alliances: The Correlates of War Formal Interstate Alliance Data Set, 1816-2000." Journal of Peace Research 41(2):211-222.

Gwet, Kilem. 2002. "Kappa Statistic is not Satisfactory for Assessing the Extent of Agreement Between Raters.".

Hage, Frank M. 2011. “Choice or Circumstance? Adjusting Measures of Foreign Policy Similarity for Chance Agreement." Political Analysis 19:287-305.

Kinne, Brandon. 2012. "Cooperation, Security, and Network Effects: Explaining the Proliferation of Bilateral Security Arrangements." Presented at the Meeting of the Peace Science Society, Savannah, Georgia.

Leeds, Brett Ashley. 2003. "Do Alliances Deter Aggression? The Influence of Military Alliances on the Initiation of Militarized Interstate Disputes." American Journal of Political Science $47(3): 427-439$.

Leeds, Brett Ashley, Jeffrey Ritter, Sara McLaughlin Mitchell and Andrew Long. 2002. "Alliance Treaty Obligations and Provisions, 1815-1944." International Interactions 28(3):237-260.

Li, Peter M. 2005. "Networks and International Relations: The Measurement of Alliance Portfolio Similarity." manuscript available online: HTTP://TERCER.BOL.UCLA.EDU/WORKSHOP/LI05.PDF (accessed December 2, 2011).

Long, Andrew G. and Brett Ashley Leeds. 2006. "Trading for Security: Military Alliances and Economic Agreements." Journal of Peace Research 43(4):433-451.

Lorraine, F.P. and H.C. White. 1971. "Structural Equivalence of Individuals in Social Networks." Journal of Mathematical Sociology 1:49-80.

Moore, Matthew. 2010. "Arming the Embargoed: A Supply-Side Understanding of Arms Embargo Violations." Journal of Conflict Resolution 54(4):593-615.

Morrow, James D. 2000. "Alliances: Why Write Them Down?” Annual Review of Political Science 3:63-83. 
Morrow, James D., Randolph M. Siverson and Tressa E. Tabares. 1998. "The Political Determinants of International Trade: The Major Powers, 1907-90." American Political Science Review 92(3):649-661.

Palmer, Glenn, Vito DOrazio, Michael Kenwick and Matthew Lane. 2015. "The MID4 dataset, 2002-2010: Procedures, coding rules and description." Conflict Management and Peace Science $32(2): 222-242$.

Rizopoulos, Dimitris. 2006. "ltm: An R Package for Latent Variable Modelling and Item Response Theory Analyses." Journal of Statistical Software 17(5):1-25.

Samejima, Fumiko. 1997. Graded Response Model. In Handbook of Modern Item Resonse Theory, ed. Wim J. van der Linden and Ronald K. Lambleton. Springer.

Signorino, Curtis S. and Jeffrey M. Ritter. 1999. "Tau-b or Not Tau-b: Measuring the Similarity of Foreign Policy Positions." International Studies Quarterly 43(1):115-144.

Sweeney, Kevin and Omar M.G. Keshk. 2005. "The Similarity of States: Using S to Compute Dyadic Interest Similarity." Conflict Management and Peace Science 22(2):165-187.

Themnér, Lotta and Peter Wallensteen. 2014. "Armed conflicts, 1946-2013." Journal of Peace Research 51(4):541-554.

Treier, Shawn and Simon Jackman. 2008. "Democracy as a Latent Variable." American Journal of Political Science 52(1):201-217.

Wagner, R. Harrison. 1984. "War and Expected-Utility Theory." World Politics 36(3):407-423.

Wasserman, Stanley and Katherine Faust. 1994. Social Network Analysis: Methods and Applications. New York, NY: Cambridge University Press. 


\section{Appendix}

Network data are often expressed in a sociomatrix, here denoted $\mathbf{P}$. Suppose we have a two sets of the same actors $i=1, \ldots, n$ and $k=1, \ldots, m$. The sociomatrix $\mathbf{P}$ is then an $n \times m$ matrix where each cell contains data about the relation among each pair of actors, $p_{i k}$. Each row, $p_{i}$, refers to the vector corresponding to State $i$ 's policy portfolio.

According to (Wasserman and Faust, 1994, p. 367), structural equivalence is defined as:

$$
d\left(p_{i}, p_{j}\right)=\sum_{k=1}^{n}\left[\left|p_{i k}-p_{j k}\right|+\left|p_{k i}-p_{k j}\right|\right]
$$

where $n$ is the number of states, $j$ and $i$ are policy portfolios, $i \neq k, j \neq k$, and $i \neq j$. Since the input data are non-directional, the absolute value of $p_{i k}-p_{j k}$ equals $p_{k i}-p_{k j}$ and is therefore equivalent to $2 \times\left|p_{i k}-p_{j k}\right|$. Equation (5) can be rewritten as:

$$
d\left(p_{i}, p_{j}\right)=2 \sum_{k=1}^{n}\left|p_{i k}-p_{j k}\right|
$$

As stated above, $S$ is a weighted and transformed version of structural equivalence as represented by Equation 6. To finish the comparison, let $w$ equal a vector of weights where $w_{k}$ is a weight for each $k$. In practice, $w$ is either uniform or corresponds to the Correlates of War's Composite Index of National Capabilities (CINC) score. If we have uniform weighting, $w_{k}$ equals $\frac{1}{n}$. In the case where $w$ corresponds to the CINC score, $w_{k}$ equals State $k$ 's CINC score in the given year for which $S$ is being calculated. By weighting in this way, one could argue that, depending on the relative power of the state, the effect of the third-party on the overall measure of foreign policy similarity is different 13

Finally, let $L$ be a vector of scoring rules which maps $p_{i}$ to some closed interval along the real number line. $\Delta^{\max }$ equals the difference between the maximum and minimum possible values after the mapping. In practice, $L$ is not used because alliances, which are integer values typically not reaching a value higher than 4 , are quite easy to work with.

As is the case in practice, we will look at the equation for calculating $S$ for a single policy dimension where the sum of the weighting vector equals 1 and we assume that no mapping for the

\footnotetext{
${ }^{13}$ However, note that the choice of weighting scheme is entirely subjective and different weights can have drastically different effects.
} 
scoring rules is necessary. Signorino and Ritter's original series of equations (p. 127) can then be rewritten as:

$$
S\left(p_{i}, p_{j}, W, L\right)=1-2\left(\frac{1}{\Delta^{\max }}\right) \sum_{k=1}^{n}\left(w_{k, k}\left|p_{i k}-p_{j k}\right|\right)
$$

Table 6: Replicating Moore's Table 3

\begin{tabular}{lrrrr}
\hline \hline & Original Results & Replicated & With $D$ & With Kappa \\
\hline$S$ score & $2.670^{* *}(1.189)$ & $2.670^{* *}(1.189)$ & - & - \\
$D$ score & - & - & - & $-0.019^{*}(0.011)$ \\
Hage's $\kappa$ & $-0.650(0.769)$ & $-0.650(0.769)$ & $-0.769(0.781)$ & $-0.788(0.749)$ \\
Arms import dep & $-0.488(0.362)$ & $-0.488(0.362)$ & $-0.728^{*}(0.366)$ & $0.684(0.540)$ \\
Military expenditure & $0.080(0.144)$ & $0.080(0.143)$ & $0.123(0.146)$ & $-0.013(0.160)$ \\
Tot ann arms imports & $-0.976(2.042)$ & $-0.976(2.042)$ & $1.444(1.692)$ & $0.416(1.736)$ \\
Arms export dep & $0.130(0.178)$ & $0.130(0.178)$ & $0.094(0.183)$ & $0.204(0.175)$ \\
\# arms trans rels & $0.460(0.888)$ & $0.460(0.888)$ & $-0.244(0.862)$ & $3.538^{*}(1.452)$ \\
Voluntary embargo & $-1.402(1.273)$ & $-1.402(1.273)$ & $-0.971(1.291)$ & $-0.311(1.285)$ \\
Comprehensive sancs & $-0.663(0.520)$ & $-0.663(0.520)$ & $-0.772(0.528)$ & $-0.100(0.551)$ \\
Cold War & $0.806(0.844)$ & $0.806(0.844)$ & $0.565(0.844)$ & $0.053(0.834)$ \\
South Africa & $0.218^{* *}(0.0975)$ & $0.218^{* *}(0.097)$ & $0.217^{* *}(0.099)$ & $0.287^{* *}(0.100)$ \\
Lagged Volume & $3.745^{* * *}(1.327)$ & $3.745^{* * *}(1.327)$ & $3.167^{* *}(1.341)$ & $\mathrm{NA}$ \\
UKR-LBY 2001 & $2.899^{* *}(1.221)$ & $2.899^{* *}(1.221)$ & $2.922^{* *}(1.238)$ & $3.242^{* *}(1.201)$ \\
ISR-ZAF 1986 & $-3.630^{* * *}(1.231)$ & $-3.630^{* *}(1.231)$ & $-3.711^{* * *}(1.247)$ & $-3.611^{* *}(1.203)$ \\
ISR-ZAF 1987 & $-4.469^{* *}(1.929)$ & $-4.469^{* *}(1.929)$ & $-5.68^{* * *}(1.967)$ & $0.264(2.552)$ \\
ERI-SOM 1999 & $6.144(5.539)$ & $6.144(5.539)$ & $12.020^{* *}(5.375)$ & $-8.743(7.932)$ \\
Constant & 8 & 89 & 89
\end{tabular}

Table 7: Replicating Fang, Johnson, and Leeds' Table 2

\begin{tabular}{|c|c|c|c|c|}
\hline & \multirow[b]{2}{*}{ Orig. Results } & \multicolumn{3}{|c|}{ 1971-2000 Subset } \\
\hline & & S-score & D-score & Hage's Kappa \\
\hline \multicolumn{5}{|l|}{ Target Resistance } \\
\hline Target's cost of damaging its alliance & $-.40 * *(.14)$ & $-.83^{*}(.32)$ & $-.77^{*}(.33)$ & $-.78^{*}(.32)$ \\
\hline Challenger has an applicable off. alliance & $-.27^{*}(.14)$ & omitted & omitted & omitted \\
\hline Challenger has an applicable neutrality pact & $-.43^{* *}(.11)$ & $-.50(.26)$ & $-.49(.26)$ & $-.46(.26)$ \\
\hline Challenger's prob. of winning in bilateral war & $.22(.12)$ & $.74 *(.31)$ & $.71 *(.32)$ & $.71 *(.31)$ \\
\hline Constant & $1.63^{* *}(.20)$ & $.98^{*}(.48)$ & $.85(.49)$ & $.92(.48)$ \\
\hline \multicolumn{5}{|l|}{ Dispute Initiation } \\
\hline \multicolumn{5}{|l|}{ Challenger-target similarity of interests: } \\
\hline S-score & $-.51^{* *}(.05)$ & $-.89 * *(.14)$ & - & - \\
\hline D-score & - & - & $.004^{* *}(.001)$ & - \\
\hline Hage's $\kappa$ & - & - & - & $.06(.06)$ \\
\hline Challenger has an applicable off. alliance & $.28^{* *}(.04)$ & $-4.10(412)$ & $-4.21(495)$ & $-4.13(389)$ \\
\hline Challenger has an applicable neutrality pact & $.41 * *(.04)$ & $.31 * *(.07)$ & $.26^{* *}(.07)$ & $.31 * *(.07)$ \\
\hline Challenger's prob. of winning in bilateral war & $-.06(.03)$ & $-.08(.07)$ & $-.13(.07)$ & $-.13(.07)$ \\
\hline Challenger-target capital-to-capital distance & $-.40 * *(.01)$ & $-.53 * *(.02)$ & $-.43^{* *}(.02)$ & $-.45^{* *}(.02)$ \\
\hline Challenger-target joint democracy & $-.06(.04)$ & $.08(.06)$ & $-.05(.06)$ & $.05(.06)$ \\
\hline Constant & $1.03^{* *}(.10)$ & $2.17 * *(.24)$ & $.77^{* *}(.16)$ & $.94 * *(.17)$ \\
\hline Rho & $-.58 * *(0.08)$ & $-.26(.14)$ & $-.22(.14)$ & $-.24(.14)$ \\
\hline Observations & 585,467 & 224,845 & 224,845 & 224,845 \\
\hline Uncensored observations & 1,085 & 267 & 267 & 267 \\
\hline
\end{tabular}


Table 8: Replicating Crescenzi et al., Table 1, Model 4

\begin{tabular}{lrrrr}
\hline \hline & & & \multicolumn{2}{c}{$1971-2000$ Subset } \\
& Orig. Results & \multicolumn{1}{c}{ S-score } & D-score & Hage's Kappa \\
\hline Alliance Reputation: & $2.82^{* * *}(0.48)$ & $1.32^{* * *}(.16)$ & - & \\
S-score & - & - & $2.00^{* * *}(.20)$ & - \\
D-score & - & - & - & $2.10^{* * *}(.22)$ \\
Hage's $\kappa$ & $1.20(2.43)$ & $2.72(3.24)$ & $2.81(3.37)$ & $2.93(3.40)$ \\
Alliance History & & & & \\
Portfolio Similarity: & $1.30^{* * *}(0.06)$ & $0.89^{* * *}(.06)$ & - & - \\
S-score & - & - & $.46^{* * *}(.03)$ & - \\
D-score & - & - & - & $.41^{* * *}(.03)$ \\
Hage's $\kappa$ & $0.22^{*}(0.09)$ & $.70^{* * *}(.15)$ & $.64^{* * *}(.15)$ & $.66^{* * *}(.15)$ \\
Interaction Score (IIS) & $0.17^{* * *}(0.02)$ & $-.10^{* * *}(.02)$ & $-.14^{* * *}(.02)$ & $-.12^{* * *}(.02)$ \\
Joint Enemy & $-.02^{* * *}(0.00)$ & $-.02^{* * *}(.00)$ & $-.02^{* * *}(.00)$ & $-.02^{* * *}(.00)$ \\
Distance & $0.38^{* * *}(0.02)$ & $.34^{* * *}(.02)$ & $.22^{* * *}(.02)$ & $.28^{* * *}(.02)$ \\
Major Power Status & $0.001(0.00)$ & $.01^{* * *}(.00)$ & $.01^{* * *}(.00)$ & $.01^{* * *}(.00)$ \\
Polity Difference & $0.30^{* * *}(0.02)$ & $.40^{* * *}(.02)$ & $.30^{* * *}(.02)$ & $.39^{* * *}(.02)$ \\
Joint Democracy & $-2.91^{* * *}(0.05)$ & $-2.45^{* * *}(.06)$ & $-1.77^{* * *}(.02)$ & $-1.84^{* * *}(.02)$ \\
Constant & 842,249 & 618,115 & 617,843 & 618,113 \\
\hline Observations & $7,033.8^{* * *}$ & $6143.24^{* * *}$ & $6952.98^{* * *}$ & $6441.24^{* * *}$ \\
Wald $\chi^{2}(9)$ & .18 & .20 & .20 & .20 \\
Pseudo $R^{2}$ & $-24,950.54$ & $-16,942.69$ & -16918.21 & -16915.14 \\
Log-likelihood & & & \\
\hline
\end{tabular}

